\title{
HIV in Women: The Gynecological Frontier
}

\author{
Goswami S, ${ }^{1}$ Chattopadhyay $\mathbf{S}^{2}$ \\ ${ }^{1}$ Department of Obstetrics and Gynaecology, \\ ${ }^{2}$ Department of Anesthesiology, Medical College and Hospital, Kolkata, India.
}

\begin{abstract}
Aims: The objective of the paper was to study the spectrum of gynecological disorders in HIV positive woman, which are often not given much importance as the issue of antiretroviral therapy and management of opportunistic infections occupy the major share of their treatment strategy.
\end{abstract}

\begin{abstract}
Methods: It was an observational study which included 135 women. The study was conducted in the Medical College and Hospital, Kolkata from January 2010 to December 2012 after obtaining permission from the institutional ethics committee. All the HIV positive women who came to the gynecological outpatient department with gynecological complaints were included in the study.
\end{abstract}

Results: The seropositive women suffered from the same range of gynecological problems as in non-infected women. The most common complaints at presentation were vaginal white discharge and pruritus vulvae. The most common postoperative complication was fever.

Conclusions: The HIV/AIDS is taking the shape of a generalized epidemic and with the advances in the antiretroviral therapy, the life expectancy of the patients is increasing. With the improvement of survival more and more of HIV positive women would present with problems pertaining to any system of the body and the gynecological complaint is not an exception. Addressing these problems would lead to boosting up of the care and support of this subset of women.

Keywords: antiretroviral therapy, gynecological problems, HIV infection, pregnancy.

\section{INTRODUCTION}

As the infection with HIV has gradually blown up to take the shape of a pandemic, the proportion of women affected by the same has also expanded. The disease has changed its character over the years and what initially emerged as a disease of gay men, now affects women and men equally. Globally women account for $50 \%$ of the people living with HIV/AIDS $(\mathrm{PLWHA})^{1}$ and in India they occupy a share of $39 \%{ }^{2}$ Majority of these women are in the reproductive age group and can suffer from the same range of gynecological problems as the non HIV population but are often overlooked. This study ventured at

\section{CORRESPONDENCE}

Dr Sebanti Goswami

Department of Obstetrics and Gynaecology,

Medical College and Hospital, Kolkata.

Email: sebantigoswami@yahoo.co.in

Phone : (+91) 9831135933 exploring the spectrum of gynecological problems amongst them.

\section{METHODS}

This observational study was conducted in the Department of Obstetrics and Gynecology, Medical College and Hospital, Kolkata from January 2010 to December 2012 after obtaining permission from the institutional ethics committee and informed consent of the patients. All the HIV positive women who attended the out patients department with gynecological problems were included in the study. All were examined, investigated and treated according

The papers in this journal are published under the terms of the Creative Commons Attribution License. Users are allowed to read, download, copy, distribute, print, search, or link to the full texts of the articles in this journal without asking prior permission from the publisher or the author. 
to their presenting complaints and diagnosis. Our institution being an apex centre for HIV, the case load is around forty patients per day. ${ }^{3}$ A total of 135 women were included in the study.

\section{RESULTS}

Out of 135 seropositive women who attended our outpatient department for gynecological problems; 41 had candidiasis, 39 had abnormal uterine bleeding, 37 had pelvic inflammatory disease, 11 women had cervical intraepithelial neoplasia (CIN), three had carcinoma cervix, two had vulval carcinoma and two women came for the treatment of infertility. Vaginal white discharge and pruritus vulvae due to candidiasis were the most common problems (Table1).

Table 1. Types of gynecological disorders $(n=135)$.

\begin{tabular}{lr}
\hline Gynecological disorder & Number (\%) \\
\hline Candidiasis & $41(30.4)$ \\
Menstrual disorder & $39(28.9)$ \\
PID & $37(27.4)$ \\
CIN & $11(8.1)$ \\
Invasive cervical & $3(2.2)$ \\
carcinoma & \\
Vulval Carcinoma & $2(1.5)$ \\
Infertility & $2(1.5)$ \\
\hline PID $=$ Pelvic Inflammatory Disease & \\
$C I N=$ Cervical Intraepithelial Neoplasia &
\end{tabular}

Menstrual abnormalities were encountered in the form of menorrhagia, metrorrhagia and menometrorrhagia. The most common cause was fibromyoma of uterus. Other causes of abnormal menstruation were cervical polyp, adenomyosis, abnormal uterine bleeding and carcinoma cervix. We did not come across any case of secondary amenorrhoea (Table 2).

Table 2. Causes of abnormal menstruation $(n=39)$.

\begin{tabular}{lr}
\hline Causes & Number (\%) \\
\hline Uterine Leiomyomas & $19(48.7)$ \\
Abnormal uterine bleeding & $9(23.0)$ \\
Adenomyosis & $7(17.9)$ \\
Polyp & $4(10.2)$ \\
\hline
\end{tabular}

Out of the 37 women who had pelvic inflammatory disease, nine had tubo-ovarian mass and underwent laparotomy. All of these women came with the complaint of chronic pelvic pain with intervening acute episodes. Eleven women had cervical dysplasia on Pap smear. Seven had low grade squamous intraepithelial lesion and four had high grade squamous intraepithelial lesion. Out of the three cases of carcinoma cervix one was an operable case (stage IIA) and two were inoperable (stage III). Two women presented with the complaint of an ulcerative swelling of the vulva. Biopsy proved them to be vulvar carcinoma. Two women came with the complaint of infertility. One of them had a history of medical termination of pregnancy done five times previously and both her fallopian tubes were blocked. Twenty six women required surgical interference (Table 3). The most common postoperative complication was fever (Table 4). All the twenty six women who were operated had CD4 count above 350. Viral load could not be done as it could not be afforded by our patients. Eleven of these operated women were on highly active anti-retroviral therapy.

Table 3. List of gynecological surgery performed $(\mathrm{n}=\mathbf{2 6})$.

\begin{tabular}{lr}
\hline Surgery performed & Number (\%) \\
\hline Total abdominal & Total $=13(50 \%)$ \\
hysterectomy & \\
Fibromyoma & $7(53.8 \%)$ \\
Adenomyosis & $2(15.3 \%)$ \\
High grade SIL & $4(30.7 \%)$ \\
Laparotomy for Tubo & Total $=9(34.6 \%)$ \\
Ovarian mass (TO) & \\
$\quad$ \#TAH with BSO & $2(22.2 \%)$ \\
$\quad$ Removal of TO mass & $7(77.7 \%)$ \\
Radical Hysterectomy & $1(3.8 \%)$ \\
Radical Vulvectomy & $2(7.6 \%)$ \\
Lap chromopertubation & $1(3.8 \%)$ \\
\hline \#TAH with BSO $=$ Total abdominal hysterectomy with bilateral \\
salpingoophorectomy
\end{tabular}

Table 4. Complications following surgery $(n=26)$.

\begin{tabular}{lr}
\hline Complications & Number (\%) \\
\hline Fever & $5(19.2 \%)$ \\
Post-operative nausea and & $4(15.3 \%)$ \\
vomiting & $2(7.6 \%)$ \\
Wound infection & $1(3.8 \%)$ \\
$\begin{array}{l}\text { Bleeding PV following } \\
\text { hysterectomy }\end{array}$ \\
\hline
\end{tabular}

\section{DISCUSSION}

Though HIV positive women have the same gynecological problems as the non-infected women, often the gynecological problems take a backseat as the acute problems related to HIV infection get precedence. Apart from the usual gynecological problems as encountered in the HIV negative women, the seropositive woman may suffer from consequences 
of the infection / antiretroviral treatment. Women with lack of access to high-quality HIV care and belonging to poor socioeconomic status are disproportionately affected by the HIV epidemic. Gender norms and, in some cases, fear of violence makes it difficult for women to refuse unprotected sex, and can contribute to higher infection rates in women and delayed entry to care. ${ }^{4}$ It has also been reported that women may have a faster disease progression than men with equivalent viral loads and are more likely than men to develop bacterial pneumonia and may have higher rates of sexually transmitted diseases. ${ }^{5}$

HIV has been recognized as an independent risk factor for the development of cervical abnormalities. HIV positive women are more likely to be infected with multiple strains of oncogenic Human Papilloma Virus (HPV) genotype. ${ }^{6}$ The HPV viral load in their cervical secretions have been found to be higher and the HPV infection are more persistent among them. The reason for this is not yet fully understood, but it may be because clinical expression of HPV infection is dependent on systemic and local cell mediated immunity which are both suppressed in HIV infection. ${ }^{7}$ The likelihood of regression of cervical intraepithelial neoplasia is decreased in HIV positive women and there is more rapid progression to invasive carcinoma. The recurrence rate of cervical intraepithelial neoplasia following treatment is also higher in this subset of patients. In our study also, 11 women had cervical dysplasia on Pap smear. Seven had low grade squamous intraepithelial lesion, four had high grade squamous intraepithelial lesion and three had cervical carcinoma (Table 1).

Abnormal uterine bleeding often encountered in seropositive women may have an array of causes. Many studies have tried to find an association between high viral load, low CD4 counts and abnormalities of cycle length. A large study on HIV positive and high risk HIV negative women from the HIV Epidemiology and Research Study (HERS) and Women's Interagency HIV Study (WIHS) declared that the serostatus had very little contribution in alteration of cycle length. ${ }^{8}$ Other studies by Harlow et $\mathrm{al}^{9}$ and Ellerbrock et $\mathrm{al}^{10}$ also do not show much of a difference in the cycle length of HIV positive women. However abnormality of menstruation may be attributable to some confounding variables like drug abuse, acute weight loss or chronic disease.

Candidiasis is commonly associated with HIV infection as also seen in our study (Table 1). The infection tends to be more severe and persistent. Various studies have shown the association between low CD4 count and increased preponderance of candidiasis thus indicating the role of immunosuppression. ${ }^{11}$ However, it is not clear whether antiretroviral therapy improves the infection. Recurrence is also quite common among this subset of women and they require long term therapy with weekly Fluconazole.

The prevalence of pelvic inflammatory disease in seropositive women has been found to be higher than that in the non-infected population. We had the similar finding (Table 3). In an analysis of hysterectomy specimens Kerr et $\mathrm{al}^{12}$ found endometritis to be twice more common in HIV positive than in HIV negative women. Some of the studies even suggested that the course and clinical presentation of pelvic inflammatory disease in HIV positive women may be more severe. ${ }^{13}$

The association between vulvar carcinoma and HIV is not as strong as that of cervical carcinoma. We got two cases (Table 1), both were relatively young (one 32 years and the other 37 years) compared to the usual age of incidence of vulvar carcinoma (around 60 years). Casolati et al ${ }^{14}$ stated in their review of vulval neoplasia in HIV positive women, that in recent years increased prevalence and incidence of high grade vulval intraepithelial neoplasia and vulvar invasive carcinoma in young patients (below 45 years of age) have been reported. The main group of affected cases is represented by HIV infected women.

The patients having HIV have multisystem involvement. Concurrently, anti-retroviral therapy has significant side effects. There are concerns regarding cardiac problems (myocarditis, cardiomyopathy, accelerated atherosclerosis) with protease inhibitors, respiratory opportunistic infections (bacterial pneumonias and aspergillosis), central nervous system involvement (encephalopathy, demyelinating syndromes, infection induced space occupying lesions, dementia among others), diarrhea along with associated electrolyte abnormalities, nephropathy (may be associated with protease inhibitors like adefovir and indinavir), pancytopenia (aggravated by nucleoside reverse transcriptase inhibitors (NRTIs), thrombotic episodes in late stages, metabolic problems (lipodystrophy, insulin resistance aggravated by protease inhibitors), lactic acidosis and pancreatitis with NRTIs, allergic reactions and hepatic involvement with non-nucleoside reverse transcriptase inhibitors (NNRTIs), apart from autonomic and peripheral neuropathy which are quite common in HIV positive patients. ${ }^{15}$ Oropharyngeal and esophageal pathology may make some patients 
susceptible to difficult intubation, regurgitation and aspiration. ${ }^{16}$ Protease inhibitors and non-nucleoside reverse transcriptase inhibitors are the most commonly implicated group of anti-retrovirals in drug interactions.

The choice of anesthesia for these patients has to be a judicious one taking into account the physical status of the patient along with investigations like complete hemogram, CD4 counts, electrocardiogram, chest $\mathrm{X}$ ray, coagulation screen, electrolyte status and assessment of liver function and renal function in all patients. Both general and regional anesthesia has been given in women having HIV. Of central concern is the fact that under no situation should the patient stop the anti-retroviral therapy. General anesthesia is acceptable but drug interactions, multisystem involvement of the disease process and transient immune suppression should be considered. Regional anesthesia is safe but one must take into consideration the presence of local infections, bleeding problems and neuropathies. ${ }^{17} \mathrm{We}$ have chosen to give subarachnoid block to most of our patients (Table 3 ). This is based on evidence to show that this technique is not detrimental to HIV infected patients except in cases where it is clearly contraindicated. ${ }^{14}$ Only concerns about adequate relaxation and longer duration of operative procedures prompted administration of general anesthesia. Though epidural anesthesia has been given in HIV patients, we avoided this techniqueas epidural catheters may act as a source of post-operative infection.

A decade or two ago the point of addressing the issue of infertility in HIV positive couples was out of question. Even drastic steps like tubectomy were undertaken and advised to prevent the HIV infected women from getting pregnant as the life span of these individuals was thought to be limited and preventive measures against mother to child transmission of HIV were also not well outlined. But with the advent of Highly Active Antiretroviral Therapy (HAART) and emerging efficient regimes for prevention of parent to child transmission the situation has changed. Infertility can be due to tubal blockage as a consequence of pelvic inflammatory disease or due to anovulation due to premature ovarian failure. One of the women in our study had undergone medical termination of pregnancy five times as she was advised by medical practitioners to do so because of the chance of transmission to her newborn. She herself did not understand the fact that HIV is a lifelong disease and she wanted motherhood in future because of personal and social implications. She had bilateral tubal block. Down the years we are witnessing a share of discordant couples who desire to have children without transmitting infection to their partners. In these cases the issues of advanced infertility treatment like donor intrauterine insemination and sperm washing need to be addressed. We are not far from the time when management of HIV infected couples will become an important problem, making its own niche in the domain of infertility.

\section{CONCLUSIONS}

HIV/AIDS has become such an entity since its inception into human race, that its killing power is much focused along with the stigma and discrimination that surround it. Often we forget the individual and start concentrating only on the HIV status and the symptoms associated with it, forgetting the fact that like any other individual they are also human beings who may require care for disorders pertaining to any system of the body which might not be related to the positive serostatus, one such area is the gynecological disorder in women. Every seropositive woman needs to be reviewed for her gynecological problems too. This is becoming essential with more and more women having longer life span due to the entry of more effective drugs into the armamentarium of antiretroviral therapy.

\section{REFERENCES}

1. UNAIDS Report on the Global AIDS Epidemic 2012. [cited 2013 July 19]. Available from http://www.unaids. org/en/resources/campaigns/20121120_global report 2012 / global report

2. National AIDS Control Organization Annual Report 2011-2012. [cited 2013 July 19]. Available from http:// www.aidsdatahub.org/sites/default/files/ documents / NACO_Annual_Report_2011_12.pdf

3. Talukdar A, Ghosal MK, Sanyal D, Talukdar PS, Guha P, Guha SK, et al. Determinants of quality of life in HIVinfected patients receiving highly active antiretroviral treatment at a medical college ART center in Kolkata, India. Journal of International Association of Providers of AIDS Care. 2013;12(4):284-90.

4. Aziz M, Smith KY. Treating women with HIV: is it different than treating men? Curr HIV/AIDS Rep. 2012;9(2):171-8.

5. Zorrilla CD. Antiretroviral combination therapy in HIV-1 infected women and men: are their responses different? Int J Fertile Womens Med. 2000;45(2):195-9. 
6. Levi JE, Fernandes S, Tateno AF, Motta E, Lima LP, Eluf-Neto J, et al. Presence of multiple human papillomavirus types in cervical samples from HIV-infected women. Gynecol Oncol. 2004;92(1):225-31.

7. Sun XW, Kuhn L, Ellerbrock TV, Chiasson MA, Bush TJ, Wright TC Jr. Human papillomavirus infection in women infected with the human immunodeficiency virus. N Engl J Med. 1997;337(19):1343-9.

8. Zierler S, Mayer K, Moore J, Stein M, Schoenbaum E, Schuman P, et al. Sexual practices in a cohort of US women with and without human immunodeficiency virus. HIV Epidemiology Research Study. J Am Med Women's Assoc. 1999;54(2):79-83.

9. Harlow SD, Schuman P, Cohen M, Ohmit SE. Effect of HIV infection on menstrual cycle length.J Acquir Immune Defic Syndr. 2000;24(1):68-75.

10. Ellerbrock TV, Wright TC, Bush TJ, Dole P, Brudney $\mathrm{K}$, Chiasson MA. Characteristics of menstruation in women infected with human immunodeficiency virus. Obstet Gynecol. 1996;87(6):1030-4.

11. Duerr A, Heilig CM, Meikle SF, Cu-Uvin S, Klein RS, Rompalo A, et al. Incident and persistent vulvovaginal candidiasis among human immunodeficiency virusinfected women: risk factors and severity. Obstet Gynecol. 2003;101(3):548-56.
12. Kerr-Layton JA, Stamm CA, Peterson LS, McGregor JA. Chronic plasma cell endometritis in hysterectomy specimens of HIV-infected women: a retrospective analysis. Infect Dis Obstet Gynecol. 1998;6(4):186-90.

13. Irwin KL, Moorman AC, O'Sullivan ML. Influence of human immunodeficiency virus infection on pelvic inflammatory disease. Obstet Gynecol. 2000;95(4):52534.

14. Casolati E, Agarossi A, Valieri M, Ferrazzi E. Vulvar neoplasia in HIV positive women: a review. Med Wieku Rozwoj. 2003;7(4 Pt 1):487-93.

15. Hignett R, Fernando R. Anesthesia for the pregnant HIV patient. Anesthesiol Clin. 2008;26:127-43.

16. Parthasarathy S, Ravishankar M. HIV and anesthesia. Indian J Anaesth. 2007;51:91-9.

17. Avidan MS, Groves P, Blott N. Low complication rate associated with cesarean section under spinal anesthesia for HIV-1 infected women on antiretroviral therapy. Anesthesiology. 2002;97(2):320-4. 